\title{
An appraisal of hypnosis
}

\author{
H. MERSKEY \\ M.A., D.M., D.P.M. \\ Physician in Psychological Medicine, The National Hospitals for Nervous Diseases, \\ Queen Square, London, and Maida Vale, London
}

\begin{abstract}
'There is no doubt that Freud is right in his remark that the eager readiness of the medical profession to employ the term "suggestion", is due not so much to the propagandism of the Nancy school as to the alleviating discovery that a great economy of thought can thereby be effected' (Jones, 1910).
\end{abstract}

Hypnosis tends today to be little used in psychiatric practice. Occasionally it is employed, as a useful adjunct to psychotherapy or manipulation of the environment, in the treatment of patients with hysterical conversion symptoms. A relaxation procedure with or without hypnotic suggestions may be followed in the treatment of specific phobias (which are rare), or in the treatment of tension headachewhich is common but far more often treated with psychotherapy and medication. Claims are made for its use in psychosomatic conditions, e.g. warts or asthma, and in the treatment of pain in childbirth. But typically, in such instances, warts respond to alternative means of suggestion, whilst asthma benefits most in respect of patients' reports of subjective well-being but very much less in regard to physical indices like vital capacity (Maher-Loughnan \& Kinsley, 1968; Maher-Loughnan, 1970). Similarly pain in childbirth is only relieved erratically, and probably not more than moderately, by hypnosis, so that whilst relaxation training is widely practised (Chertok, 1969) hypnosis itself is rarely used. In this country there are one or two research workers in the field of hypnotism and systematic experimental work is conducted by a number of psychologists in North America. In the U.S.S.R. the subject attracts attention, in a framework of Pavlovian theory. The writer only uses the technique occasionally but has employed it from time to time in the past, and many, perhaps most, psychiatrists in the U.K. do not use it at all. Nevertheless the subject remains of considerable theoretical and human interest.

\section{The common phenomena}

The following brief description of the technique and phenomena of induction of a hypnotic state, will serve as an introduction to considering the nature of the condition.
As a preliminary the hypnotist attempts to estab $\bar{\omega}$ lish the patient's confidence in him and also hiso willingness to co-operate, since hypnosis cannot be induced without co-operation. In most techniques the recumbent patient is required to fixate his eyes on a point slightly above and forwards, to breather slowly and deeply, and to consciously relax hiser muscles. Suggestions are then given that he will go to sleep: 'Your eyes feel heavy and they are slowlyo closing. You won't be able to keep them open. The eyelids are getting heavier and heavier and closer and closer together. It is more and more of an effort tœo keep them open . . . you can't keep them open a面y号 longer . . . If the patient is susceptible his eyes wdil close in about 5 or $10 \mathrm{~min}$, sometimes, in fact frequently, if the attempt is made to produce a quick result, he will close them within 2 or $3 \mathrm{~min}$. This दुso the first stage of hypnosis. Suggestions are then given that the sleep is deepening, the relaxation more pro-o found. In the second stage of hypnosis the subject oro patient apparently loses his ability to control his@ muscles voluntarily. A convenient way to test this is $\overrightarrow{\vec{O}}$ to give the suggestion that one arm is rising from the 3 couch. As this suggestion is repeated, intensively, the arm will rise slowly into the air. At this point the suggestion can be given that the arm has gone stiffo when the patient will find that he can no longer move 3 . his arm until told to do so. This level of hypnosis is suitable for most treatment. The third stage of hypnosis is the somnambulist, in which the patient cano walk about although still hypnotized. It is at this stage that some of the more curious phenomena can? be observed, e.g. pinprick is not only unfelt but $>$ bleeding may not occur. This level of hypnosis is only attained by a minority of subjects and although it is used in research, it is often not necessary in medical treatment. In the second and third stages of 0 hypnosis, psychogenic paralysis, amnesias, anaes- $\omega$ thesias and even hallucinations or false beliefs may be induced or abolished. Suggestions may be given dur-o ing the session to carry out various actions either $\bar{\varnothing}$ immediately or after the session has finished. Those ${ }^{+}$ which are intended to take effect later are known as 0 post-hypnotic suggestion and make subsequent 
induction easier (Merskey \& Tonge, 1965). The practice of hypnosis is relatively easy for anyone who has an interest in undertaking it and, despite the potential drama, the procedure seems rather boring after a few occasions. Sim (1968) indeed puts it that if trade unions were to rate the practice of hypnotism, it would not rate higher than semi-skilled labour'. However, many striking effects are attributed to hypnosis and it is quite widely accepted that hypnosis can relieve the pain of childbirth and operations in an exceptional way even though the provision of good relief may be unreliable; it is also widely thought that a splitting of consciousness is involved as well as some physiological alterations. Since 1958 evidence has been produced in abundance which challenges the idea that these phenomena are the perquisite of a special trance state (Barber, 1969, 1970). This evidence, supporting an older view, allows a re-interpretation of hypnosis and is, in the writer's opinion, the most important psychological contribution to the topic since Freud discovered the transference in the course of hypnotic treatment. Before attempting to describe Barber's work, an account will be given of some of the history of the subject and the most relevant scientific findings.

\section{History of hypnosis}

The literature and sources on this aspect as on others to do with hypnosis is vast, and even a whole-time student of the subject would probably be unable to achieve comprehensive coverage. The most consistent theme is a relationship between hypnosis and suggestion, it being disputed whether hypnosis is nothing more than suggestion, or else a special trance state in which suggestion readily occurs. It is confidently stated (Ambrose \& Newbold, 1968) that the phenomena were known to many ancient civilizations including the early Celtic inhabitants of Britain. Cures by suggestion, perhaps involving some alteration of attitudes or apparent awareness, could probably be found throughout medical writings from antiquity to the present times. In the eighteenth and nineteenth centuries the efficacy of suggestion and hypnotic procedures was ineluctably recognized. The story commonly highlights Franz Anton Mesmer (1734-1815) a physician who combined cures with demonstrations. At first Mesmer attributed his successes to the use of magnets-genuinely believing in their powers. He soon learnt that magnets were unnecessary but continued to believe that 'animal magnetism' caused the various phenomena which he induced and he regarded 'animal magnetism' as a physiological process. The subject was investigated by a Commission appointed by Louis XVI headed by the astronomer Bailly and including Benjamin Franklin, Dr Guillotin and Lavoisier. The Bailly report (1784) described a number of hypnotic pheno- mena, accepted their reality and attributed their production to imagination not magnetism. '. . . imagination without magnetism can produce convulsions . . . magnetism without imagination has no effect at all'. D'Eslon (1780) had already remarked 'If the medicine of the imagination is best why should we not practice the medicine of the imagination?' Thus the ebb and flow of discussion and investigation resulted in an explicit distinction being made between physical effects due to physiological agents and physical effects due to psychological influences; and the psychological view was established authoritatively. Despite this, controversy and uncertainty continues to the present time. It was in the course of argument about rival explanations that Braid (1843) coined the word 'hypnotism' to emphasize the neurophysiological interpretation.

The course of the nineteenth century discussion could serve as a paradigm for the problems - and also the achievements-of research into psychological phenomena. Apart from the influence of the placebo effect and the difficulty of establishing control procedures there were problems of finding adequate concepts, exemplified by the use of terms like those already mentioned and others such as 'fluidism' and 'animist'. Moreover, as Freud was later to show, the motives of both subject and hypnotist were often neither scientific nor solely directed towards a cure. And the topic is, and was, bedevilled by the ease with which it lends itself to practice by charlatans and the uncritical. Indeed the latter are at a particular advantage since the less sceptical the practitioner is of his powers and results, the easier it is to produce impressive changes. Some of the more extreme examples of behaviour induced under hypnosis, including those alleged to support notions of extra-sensory perception, are to be found in a series of volumes edited by Dingwall (1967), and include items like reading sentences which have been completely covered over, playing cards blindfold, supposed thought-transmission and similar tricks which today would be considered essentially the province of the deliberate stage illusionist. An excellent brief but scholarly account of the history of the scientific issues is given by Chertok (1966).

It is worth remarking also that the school of Charcot noted the apparent identity of many types of hysterical behaviour with hypnosis, the same patterns of response, the same neurological characteristics in the paralysis, the tendency with hypnosis to produce dissociations of consciousness and even multiple personalities, and the particular liability of some patients with hysteria to produce the most extreme examples of hypnotic effects. In consequence hysterics can accept and act upon the most remarkable suggestions under hypnosis but at other times prove very resistant to being hypnotized. 


\section{Suggestion}

After the claim that hypnosis was a psychological process the next notable development in the nineteenth century was the increasing recognition of the importance of suggestion as a principal factor in inducing hypnotic phenomena. The development of this viewpoint is particularly credited to Hippolyte Bernheim, Professor of Medicine at Nancy. Associated with his name is that of Liébeault, a country practitioner of wide experience and great skill and integrity. Suggestion - as will be indicated-remains the most solidly established element in the hypnotic procedures. Theories of suggestion had to contend with other evidence emerging from the school of Charcot at the Salpetrière and a quotation on the matter from William James (1890) is apposite:

'The Theory of Suggestion denies that there is any special hypnotic state worthy of the name of trance or neurosis. All the symptoms above described as well as those to be described hereafter, are results of that mental susceptibility which we all to some degree possess, of yielding assent to outward suggestion, of affirming what we strongly conceive, and of acting in accordance with what we are made to expect. The bodily symptoms of the Salpêtrière patients are all of them results of expectation and training. The first patients accidentally did certain things which their doctors thought typical and caused to be repeated. The subsequent subjects "caught on" and followed the established traditions. In proof of this the fact is urged that the classical three stages and their grouped symptoms have only been reported as spontaneously occurring so far, at the Salpêtrière, though they may be superinduced by deliberate suggestion, in patients anywhere found. The ocular symptoms, the flushed face, accelerated breathing etc. are said not to be symptoms of the passage into the hypnotic state as such, but merely consequences of the strain on the eyes when the method of looking at a bright object is used. They are absent in the subjects at Nancy where simple verbal suggestion is employed. The various reflex effects (aphasia, echolalia, imitation, etc.) are but habits induced by the influence of the operator, who unconsciously urges the subject into the direction in which he would prefer to have him go. The influence of the magnet, the opposite effects of upward and downward passes, etc. are similarly explained. Even that sleepy and inert condition the advent of which seems to be the prime condition of further symptoms being developed, is said to be merely due to the fact that the mind expects it to come; whilst its influence on the other symptoms is not physiological, so to speak, but psychical, its own easy realization by suggestion simply encouraging the subject to expect that ulterior suggestions will be realized with equal ease. The radical defenders of the suggestion theory are $\frac{3}{\infty}$ thus led to deny the very existence of the hypnotic $\varrho$ state, in the sense of a peculiar trance-like condition which deprives the patient of spontaneity $\overrightarrow{\vec{F}}$ and makes him passive to suggestion from without. $\overrightarrow{0}$ The trance itself is only one of the suggestions, and $\frac{D}{0}$ many subjects in fact can be made to exhibit the $\frac{\bar{\sigma}}{\bar{\rho}}$ other hypnotic phenomena without the induction $\overparen{\nabla}$ of this one.

The theory of suggestion may be said to be quite triumphant at the present day over the neurosis $\vec{O}$ theory as held at the Salpêtrière, with its three $\overrightarrow{\vec{H}}$ states, and its definitive symptoms supposed to be produced by physical agents apart from co- $\bar{D}$ operation of the subject's mind. But it is one thing 3 to say this, and it is quite another thing to say that there is no peculiar physiological condition what- ir ever worthy of the name of hypnotic trance, no fr peculiar state of nervous equilibrium, 'hypotaxy', ir 'dissociation', or whatever you please to call it, $N$ during which the subject's susceptibility to out- 은 ward suggestion is greater than at ordinary times. All the facts seem to prove that, until this trance- $>$ like state is assumed by the patient, suggestion produces very insignificant results, but that, when of it is once assumed, there are no limits to sugge $\vec{\theta}$ tion's power. The state in question has mat affinities with ordinary sleep.'

Clearly although the importance of suggestion was well recognized by all workers, James could not rid himself of the idea that a special nervous or trance state might be occurring or some form of dissociation of consciousness. The latter was suggested by Janet, Charcot, Prince, Tuckey and numerous others, who $\overrightarrow{\overrightarrow{0}}$ took an active interest at that time in dissociations of 3 the personality and related phenomena, like hysterical fits and trances, similar hypnotically induced states and hypnotic treatment. Bernheim, despite his attack on Charcot, thought that hypnosis was a normal physiological variant of sleep. The belief in a special trance state persisted in the view of many astute workers who considered that hypnosis re- $\frac{O}{3}$ sembled sleep (Schilder, 1956) and it is still held at

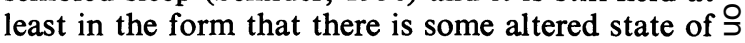
consciousness (e.g. Gill\& Brenman, 1959; Shor, 1959; Delay \& Pichot, 1962; Abse, 1966; Tart, 1969). 을 The reasons why the writer has relinquished this view $N$ will appear shortly. In essence they depend on the negative character of relevant neurophysiological 0 data and the positive nature of Barber's experimen- $\omega$ tal work. Before relating this information, it is worth-? while considering the dynamic aspects of hypnosis $\stackrel{0}{\circ}$ and the relationship with hysteria, since even though $\mathbb{\Phi}$ hypnosis may not be a special form of trance state it ${ }^{+}$ is important to examine how 'suggestion' may work. $\frac{0}{0}$ As Jones (1910) put it 'to be able to attribute a given 
occurrence to suggestion is with many a complete solution of the problem, and they do not find it necessary to pursue the matter further . . . it is striking to find what little work has been done on the question of the nature of suggestion'.

\section{The motives for suggestion}

In 1917 Freud remarked that Bernheim 'could never say what suggestion actually was or how it arises . . . he did not recognize the dependence of "suggestibility" on sexuality, or the functioning of the libido. And we have to admit that we only abandoned hypnosis in our methods in order to discover suggestion again in the shape of transference'. Freud abandoned hypnosis primarily because he discovered that it led to a special dependence upon him by the hysterical patients he treated. At first his only complaints were that he could not hypnotize every patient and that he could not always take those who were hypnotized deep enough. Then increasing experience raised doubts. He found 'even the most brilliant results were liable to be suddenly wiped away if my personal relationship with the patient became disturbed'. Then 'one of my most acquiescent patients with whom hypnotism had enabled me to bring about the most marvellous results, and whom I was engaged in relieving of suffering by tracing back her attacks of pain to their origins, as she woke up on one occasion, threw her arms around my neck. The unexpected entrance of a servant relieved us from a painful discussion, but from that time onwards there was a tacit understanding between us that the hypnotic treatment should be discontinued. I was modest enough not to attribute the event to my own irresistible attraction, and I felt that I had now grasped the nature of the mysterious element that was at work behind hypnotism. In order to exclude it or at all events to isolate it, it was necessary to abandon hypnotism.'

The power which motivated the patient to accept the hypnotic procedure was evidently not just a wish to recover, it was sexual love which would attach itself inevitably to the therapist; and hypnosis resembled love with its humble subjection and absence of criticism towards the hypnotist as towards the loved object (Freud, 1921). Moreover, the ability to be hypnotized to a varying depth has to do, as Jones (1910) put it, 'rather with some inherent faculty that varies with different subjects than with any positive action on the part of the hypnotist'. A justification or criticism of these views is beyond the scope of this article. It is sufficient for our purposes to recognize: (1) that the relationship of hypnotizer to subject is most typically, though not invariably, one in which masculine dominance attitudes are adopted by the hypnotizer and feminine-passive-compliant attitudes are displayed by the subject, who is most often female; (2) other motives, less closely tied, if at all, to sexual libido can play an important part in determining hypnotizability, e.g. valid wishes to recover, explore a new experience, or (supposedly) an extra dimension of consciousness, or to assist a scientific investigation; (3) since the ability to be hypnotized depends so much on the individual it is essential to consider the motives that lead to the acceptance of suggestion.

\section{Physiological observations}

The view that hypnosis is a trance state with a specific physiological basis gains credence in part from the supposedly far-reaching effects of hypnosis upon the body. In the sensory systems, deafness, blindness and the abolition of pain are notable changes attributed to hypnosis; similarly autonomic changes affecting the bronchioles, circulation and perhaps the skin are widely supposed to occur with hypnosis, and differences in immunological responses have been shown (Black, 1963a, b; Black, Humphrey \& Niven, 1963; Black \& Friedman, 1965). The regression of a subject to childhood and the production of an extensor plantar response, or the abolition of corneal reflexes have likewise been claimed. There is good reason however, to doubt that any of the more extreme claims of the power of hypnosis are justified. According to this view a very typical result was obtained by Malmo, Boag \& Raginsky (1954) in a study of hysterical deafness and hypnotically induced deafness. Muscle potentials were recorded and also eye-blink, and the authors describing their first hypnotic subject report '. . . in interview following the hypnotic session (she) denied hearing any sounds during the period of hypnotic deafness. Motor data . . . showed clear reaction to the first stimulus'. Subsequent motor responses were reduced significantly apart from blink, but were not wholly abolished. The discrepancy between the absolute subjective loss of hearing and the persistence of reflex response emphasizes the failure of hypnosis to fully inhibit the involuntary mechanisms of the nervous system. Similarly in regard to pain, Barber (1963) in a detailed examination of the evidence finds that 'hypnotic analgesia' may be accompanied by signs of pain and produces an unwillingness to state directly to the hypnotist that pain was experienced. Taking the most famous cases of 'painless' surgery under hypnosis, those of Esdaile, Barber finds such reports as 'she moved and moaned', 'About the middle of the operation she gave a cry', 'The man moved and cried out, before I had finished ... on being questioned he said that he had felt no pain'. Of six patients on whom Esdaile operated for scrotal tumours, three showed no gross signs of pain, but two of these three showed marked elevations of pulse rate of the order 
of 40 beats $/ \mathrm{min}$. Here and there is more than a hint that many hypnotized patients experience pain which they are reluctant to report. A striking illustration of this is provided in a report by Kaplan (1960) of a deeply hypnotized subject who was traumatized in the left arm. To the experimenter he said 'When are we going to begin?' With his right hand, which was engaged in automatic writing he had written 'Ouch, dammit, you're hurting me!' Kaplan concludes from this that the pain was experienced 'at some level' and that hypnosis produced an 'artificial repression and/or denial'. Mandy et al. (1952) similarly presented evidence that 'natural childbirth' patients who claimed not to have pain would tell independent observers that delivery was painful after all. One patient said she could not admit it to the staff for fear of disappointing them. This is not to say that pain is not susceptible to hypnosis. There is much evidence that pain is reduced by hypnosis and by a variety of other psychological influences (Barber, 1959; Merskey \& Spear, 1967). But the extent of the reduction by hypnosis is usually limited and it has not been shown that more can be done by hypnosis, either in causing or alleviating pain, than by the usual forms of psychiatric treatment or by procedures which, either necessarily or deliberately, employ placebos. In the writer's practice, which involves many patients who have pain of psychological origin and others with physical causes for their pain the use of hypnosis is negligible. Authors who have reported on the treatment of the pain in spinal cord lesions (Dorcus \& Kirkner, 1948) and in neoplasia (Butler, 1954) find the help given is often incomplete and time-consuming, and perhaps not more than could be obtained by psychological support (Butler, 1954).

Sacerdote (1965) reports partial success in the treatment of two patients with secondary carcinoma, but in one of the cases the patient required daily sessions and had much emotional support of which he was in obvious need. Sacerdote is one of the few making claims for the active use of hypnosis in the treatment of cancer (Sacerdote, 1966) and of patients with chronic protracted pain of organic origin (Sacerdote, 1962). Whilst the benefit of the hypnotist's presence can be readily understood and conceded it is by no means to be supposed that comparable effects were not obtainable by other psychological techniques.

In regard to physiological changes associated with pain Shor (1962a) found experimentally that galvanic skin response, respiration, limb movement and heart rate were favourably influenced by hypnosis and equally by the reduction of anxiety without hypnosis. From this work and from a review of other papers on the physiological variables associated with pain (Shor, $1962 b$ ) he concludes that 'hypnotic analgesia is one means of eliminating the incidental anxiety com-ðֶ ponent of the total pain experience'.

As Barber has emphasized there are three con- $\frac{\mathbb{D}}{\not{Q}}$ clusions, amongst others, which can be drawn frome.

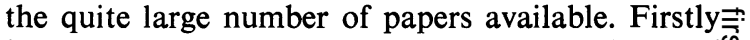
hypnotic subjects do give behavioural evidence of $\stackrel{\text { ? }}{+}$ experiencing pain, secondly they tend to deny the experience of pain to the hypnotist-but acknow- $\frac{\bar{\sigma}}{\overline{5}}$. ledge it to others, and thirdly hypnosis has not been shown to produce more effect than other techniques. $\stackrel{2}{2}$ Where it has been directly compared with them as by Shor (1962a) and Barber \& Hahn (1962) the re- 0 sponses of the hypnotic group and of the others are more or less the same.

The limited nature of the hypnotic effect can like-s wise be seen in studies of the circulation. Black et al: (1963) found no interaction between hypnosis and thermal body changes. Only small effects were ob- $-\vec{v}$ served with the induction of hypnosis on hand bloodis flow, pulse and respiration and none on forearmo blood flow. In a few experiments marked changes in forearm blood flow occurred which appeared to $\mathrm{N}_{0}^{\mathrm{N}}$ resemble changes in the circulation caused by emo- tional stimuli. A failure to show more than minor physical changes in the vital capacity of asthmaticse has already been mentioned. Experiments whighc claimed to show the unilateral abolition of wants (Sinclair-Gieben \& Chalmers, 1959) have not aqu -6 parently been replicated (the writer once tried this. unsuccessfully). There is an impressive report (Blas, 1936b) of the effect on hypersensitivity where directs suggestion under hypnosis showed very marked to $\bar{\partial}$ moderate degrees of instant inhibition, in eight subjects out of twelve, of the immediate-type (Prausnitz- $\mathbb{D}$ Küstner) hypersensitivity response. Even here how- $\vec{F}$ ever the control comparison was with the normals waking state and not with non-hypnotic suggestion.? Thus the peripheral physiological effects of hypnosis like its effect on pain, are less impressive than is some $=$ times thought and comparable results appear to be 3 attainable by other psychological techniques.

Another possibly significant area of physiologicap. knowledge has to do with so-called animal hypnosis An excellent account of this and of related phen omena is given by Oswald (1962). The classical ex-응 periment in this field was conducted in 1646 by the Abbé Kircher who described how a trance state of을 immobility could be brought about in a chicken by seizing it and holding the head and trunk motionless in an unnatural position. Similar 'death feigning' or 0 'still reactions' have been reported to occur in al $\hat{W}^{\circ}$ varieties of creatures from cockroach to primate Oswald states that a response can be provoked by overwhelming fear, monotonous stimulation anc imposed restriction either separately or in combina? tion. The initial condition is one of immobility, witho extreme alertness and increased muscular tension 
passing into a condition of light sleep lasting for a matter of minutes or more. The EEG changes are first those of alertness and then those of sleep. A similar condition has often been induced in animals subjected to insoluble conflict situations in the course of laboratory experiments. This condition is often described as an inhibitory experimental neurosis and was observed first by Pavlov. Some writers have seen a similarity between animal hypnosis and human hypnosis. Chertok (1966) observed that a living organism always requires to react to the outside world, and if this interaction is interrupted or altered, the organism may react by adopting a regressive attitude. He claimed that this is precisely what happens in both animal and human hypnosis, and this common factor provides the basis for a fundamental similarity in the two forms of hypnosis. The writer does not find this view convincing. Animal hypnosis-so-called-is a condition of immobility with tension. Human hypnosis is generally one of relaxation but not necessarily immobility. A varied response is possible for the hypnotized human subject but does not appear to occur in the animal case. Natural sleep seems to be the usual sequel to animal hypnosis and it is a relatively rare one in the human. The biological significance of animal hypnosis is that producing immobility helps in the avoidance of notice by predators. None of this would apply to human hypnosis except by very far-fetched argument. There are conditions in man which seem to resemble animal hypnosis somewhat more, and they are generally forms of stupor. Catatonic stupor and, to a lesser extent, depressive stupor are somewhat like animal hypnosis, in their lack of response to communications and stimuli. Some cases of stupor provoked by organic brain damage, may also be held to resemble animal hypnosis. Again they are distinct from conventional human hypnosis both by virtue of the presence of organic disease and, as with stupors caused by psychosis, in the failure of the affected person to respond to instructions and communications. It seems reasonable to conclude that phenomena of this type are very different from the sort of conditions that are called hypnosis in man.

Hypnosis also differs from natural sleep. The EEG of natural sleep passes through several stages but is different in readily recognizable ways from that of the waking state. The EEG under hypnosis remains little changed from, if not identical with, that of the waking condition, except when after a while the subject may become unresponsive to hypnotic commands or enquiries because natural sleep has supervened. Such small changes as may be seen in the EEG under hypnosis can be related to variations in attention, relaxation and emotion. These simple wellknown data were at first very surprising and in some ways a disappointing discovery. It might have been confidently expected that the EEG of the hypnotized subject would show some alteration which enabled us to classify it with organic or physiological disturbances of consciousness, perhaps in the same group but with distinctive features of its own. In that event one of the most fascinating psychological problems could have been understood or re-interpreted in terms of cerebral physiology. So far this has not been possible, and indeed if we take the psychological evidence seriously it is not very likely that it will be possible until we can describe thought processes and the complexities of interpersonal behaviour in physiological terms. An investigation which confirms this lack of recognizable cerebral physiological changes under hypnosis was reported by Halliday \& Mason (1964). These investigators recorded somatosensory and auditory evoked potentials and found no difference in the potentials between the normal state and that following hypnotically induced sensory loss. This negative finding is important, particularly because it was not the result which the investigators might well have anticipated. But it fits extremely well with the view that hypnosis (and hysteria) do not prevent the registration of sensory impulses or even their cerebral processing. And if one accepts that hypnotic subjects are engaging in denial of experience rather than managing to block their sensory input then this result is in precise accordance with expectation. Nonetheless the attempt to find a physical basis for hypnosis in brain activity is not readily jettisoned and authors can still be found who try, much in advance of currently available knowledge, to locate the mechanism of hysteria and hypnosis in the reticular activating system.

\section{Expectation and hypnotic behaviour}

Even if hypnosis is not sleep we are still left with the problem as to whether hypnosis is a special form of trance or altered consciousness. Evidence in regard to this has already been touched on. It is considered in detail by Barber (1969) who on the basis of much experimental evidence offers the view, in essence, that hypnosis is a pattern of behaviour which depends upon expectation and suggestionand it is nothing more.

Barber's argument runs somewhat as follows:

From the standard accounts of hypnotic behaviour we can abstract two patterns. One, the response to test-suggestions is elicited by suggesting that the subject cannot unclasp his hands or bend a knee or feel stimuli. He is told-and acts accordingly-that he will see or hear things not present, forget everything that has occurred and will undertake posthypnotic acts which are sometimes bizarre or comical. The second pattern is of limpness-relaxation, lack of spontaneity, fixity of the eyes and psychomotor retardation. In addition patients will later state 
that they were hypnotized to a light, medium or deep level. From these observations two assumptions are commonly made: (1) that a special trance state occurred and (2) that this state is an instrumental factor in producing the patterns of behaviour described. From the earlier discussions it will be seen how tenuous are these explanations. A scientific approach requires that we specify independent (antecedent) and dependent (consequent) variables and that we determine their relationship empirically. In hypnosis the dependent variables are the well recognized behaviour patterns just mentioned. The independent variables are less obvious. The first group includes the instructions or suggestions employed in hypnotic induction. Besides the usual pattern this means such subtle features as tone of voice, method of presentation (e.g. orally or by taperecording) and the specific wording of the questions used to elicit subjective testimony. For example, with respect to amnesia the wording of an enquiry may vary from 'Tell me everything that you remember' to 'Have you forgotten everything that occurred?'

A second group of independent variables includes the personality characteristic of the subject, his attitudes and expectations. A third group relates to the experimenter's status, personality, attitudes and expectations. Lastly a fourth group relates to the personality interactions between hypnotist and subject. When these variables are systematically studied it becomes possible to show that each of them influences the outcome of hypnosis. Thus investigators use a more forcible tone with hypnotic than non-hypnotic subjects. If this is controlled by tape-recording the experimental results are the same for hypnotic and non-hypnotic groups. Another example may be found in the way phrasing of questions influences responses (Barber, Dalal \& Calverley, 1968). In one group asked 'Did you feel you could not resist the suggestions?' the answer is usually 'Yes'. In a second group asked 'Did you feel you could resist the suggestions?' the answer is also usually 'Yes'. These groups will likewise testify appropriately that they felt hypnosis was basically similar to, or different from, the waking state, depending upon the way the question is put to them.

Barber claims that the reasoning which requires us to suppose that these changes depend on a trance state is basically circular and invalid. In effect the subject is told he will feel relaxed and act differently. We see him relax and act differently and we assume that he was 'hypnotized' into a trance state. As Chaves (1968) puts it, the presence of the hypnotic state is inferred from criteria which are inseparable from responses to suggestions, and a circular explanation is difficult to avoid because the hypnotic construct is used to explain responses to suggestions.
Trance depth is similarly inferred from the behaviouro it is supposed to explain. The more the subject carried 3 out waking suggestions to hallucinate, stand on his@ head or forget everything that occurred, the deeper. we say was the trance depth. Subjects follow the same $\overrightarrow{\bar{c}}$ lead and say they were deeply hypnotized because ${ }^{+}$ they followed the various suggestions (Barber \& $\frac{\mathrm{C}}{\mathrm{C}}$ Calverley, 1966). Yet, if instructions are given which $\overline{\bar{c}}$. strongly motivate subjects to carry out the tasks setthem, results can be achieved comparable with those of suggestion under hypnosis. Barber calls these in $-\infty$ structions 'task-motivating'.

For the most economical explanation it is un necessary to postulate a special trance state. Thew more one looks at the subject's expectations, the things said to him, and the questions put to elucidate what occurred, the clearer it becomes that hypnotic phenomena are determined by the antecedent variables and not by any other peculiar intervening con- 교 dition. Not surprisingly these antecedent variables work best to produce 'hypnotic' changes where the result depends most on the subject's agreement ando testimony (as with suggested deafness) and less or? not at all where the dependent variable is a physio $\rightarrow$ logical change, or an independently measurable change for which input has to be abolished. Subjeetsen reporting total or partial deafness produced with, or even without, an hypnotic induction procedue,$v$ showed stuttering and mispronunciations under com-ditions of delayed auditory feedback in the same wiy as persons with normal hearing (Barber \& Calverley, 1964). The phenomena of hypnosis then are to be explained as responses to suggestions carried out ink accordance with the subject's initial expectations $\stackrel{\mathbb{\Omega}}{\Omega}$ Those expectations are determined by his previous idea of what is to happen and especially by the way 3 in which the hypnotist presents the situation? Barber gives credit to Sarbin (1950) and to others foro similar prior formulations but there is no doubt that his is the most radical and extensive revision of the concept of the hypnotic state.

Despite the range, skill and logic of Barber's work not everyone has been convinced by it. There is ao general recognition that he has shown much of interest concerning the interpersonal factors and other variables promoting change under hypnotic suggestion. Chertok (1966) expresses his reservations by arguing, that as with Bernheim, those who wish ton assimilate hypnosis to suggestibility continue to use the techniques of instruction in hypnotic induction thereby showing a lack of consistency. This does notw appear to be true of Barber however since he has? carefully used the techniques of hypnosis in ordero to compare them with non-hypnotic suggestibility $\bar{\Phi}$ One wonders what he should have been asked to do?

Some criticisms of Barber's work have been made 0 both on theoretical and experimental grounds, buP 
none of them appears weighty. Hilgard (1964) seems to suggest that Barber's control condition, in which subjects may be asked to imagine something, is a type of hypnotic induction and thus that his results with 'control' subjects can be attributed to hypnosis. Evans (1966) offers a similar argument. Evans and also Bowers (1966) argue that Barber's demonstrations that hypnosis and suggestion in the form of taskmotivating instructions produce the same results do not disprove the occurrence of a trance state; which is true but scarcely proves the existence of a hypnotic trance state. Chaves (1968) supports Barber and points out that if subjects who are instructed to imagine vividly are being exposed to a hypnotic induction procedure, we cannot draw a line separating those instructions which constitute a hypnotic induction procedure from those which do not. In any case there is little justification for labelling instructions to imagine as a 'hypnotic induction' unless we are able to demonstrate that they produce a state of hypnosis. On the other hand Barber's critique of the methods used so far to infer the presence of the presumed hypnotic state have not been criticized by Hilgard or by Evans.

Conn \& Conn (1967) criticized Barber for failing to consider important variables like 'primitive transference motivations', 'need gratifications', 'human variables' and 'the willingness and trust of the subject'. Barber has suggested that these and other variables should be evaluated empirically. It is not a fault in his theories that he has failed to lay much emphasis on these particular motivational variables since his theory can stand with or without discussion of them. However, it would probably help to give a more complete explanation of hypnosis, along the lines which Barber uses, if attention were to be paid in the future to both the unconscious and conscious motivations which incline people to be subjects for 'hypnotic induction'.

Experimentally Hilgard \& Tart (1966) have attempted to show that Barber's failure to find differences between the effects of task-motivating instructions and a hypnotic induction procedure was because he did not use a design sensitive enough to detect differences. Their own design and conclusions have been criticized by Chaves (1968) who finds that the most appropriate interpretation is that Hilgard \& Tart in fact confirmed Barber \& Calverley's (1966) findings that, as compared with an unmotivated control treatment, hypnotic induction procedures produced a small increment in suggestibility.

In essence Barber's argument is that what happens in hypnosis depends on the preconception of the participants.

The writer considers Barber's case to be wellestablished. A Freudian explanation is helpful in addition in understanding some of the motives in- volved. Why people accept suggestion must be considered as well as how they respond to it. Further the acceptable physiological evidence shows (a) that hypnosis does not produce results which are unobtainable by other psychological means and (b) there is no detectable change in cerebral activity as a special result of hypnosis.

In these circumstances we can describe the nature of hypnosis as follows:

The nature of hypnosis. Hypnosis is a manoeuvre in which the subject and hypnotist have an implicit agreement that certain events (e.g. paralysis, hallucinations, amnesias) will occur, either during a special procedure or later, in accordance with the hypnotist's instructions. Both try hard to put this agreement into effect and adopt appropriate behavioural rules and the subject uses mechanisms of denial to report on the events in accordance with the implicit agreement. This situation is used to implement various motives whether therapeutic or otherwise, on the part of both participants. There is no trance state, no detectable cerebral physiological change, and only such peripheral physiological responses as may be produced equally by non-hypnotic suggestion or other emotional changes.

\section{References}

Abse, W. (1966) Hysteria. John Wright, Bristol.

Ambrose, G. \& Newbold, G. (1968) A Handbook of Medical Hypnosis. Baillière, Tindall \& Cassell, London.

BAILly, J.S. (1784) Rapport des Commissaires Chargés par le Roi de l'Examen du Magnetisme Animale. Imprimerie Royale, Paris, cit. Chertok, 1966.

BARBER, T.X. (1959) Toward a theory of pain: relief of chronic pain by prefrontal leucotomy, opiates, placebos and hypnosis. Psychological Bulletin, 56, 430.

BARBER, T.X. (1963) The effects of hypnosis on pain. A critical review of experimental and clinical findings. Psychosomatic Medicine, 25, 303.

BARber, T.X. (1969) A Scientific Approach to Hypnosis. Van Nostrand, Princeton.

BARBER, T.X. (1970) Suggested ('hypnotic') behaviour. In: The Trance Paradigm Versus an Alternative Paradigm. Harding, Mass. Medfield Foundation.

BARBER, T.X. \& CAlverley, D.S. (1964) Experimental studies in hypnotic behaviour. Suggested deafness evaluated by delayed auditory feedback. British Journal of Psychology, 55, 439.

BARBER, T.X. \& CALVERLEY, D.S. (1966) Effects on recall of hypnotic induction, motivational suggestions, and suggested regression: a methodological and experimental analysis. Journal of Abnormal and Social Psychology, 71, 169.

Barber, T.X., Dalal, A.S. \& Calverley, D.S. (1968) The subjective reports of hypnotic subjects. American Journal of Clinical Hypnosis, 11, 74.

BARber, T.X. \& HAHN, K.W. (1962) Physiological and subjective responses to pain-producing stimulation under hypnotically-suggested and waking-imagined 'analgesia'. Journal of Abnormal and Social Psychology, 65, 411.

BLACK, S. (1963a) Inhibition of immediate-type hypersensitivity response by direct suggestion under hypnosis. British Medical Journal, 1, 925. 
BLACK, S. (1963b) Shift in dose-response curve of PrausnitzKüstner reaction by direct suggestion under hypnosis. British Medical Journal, 1, 990.

BlaCK, S., EDHOLM, O.G., Fox, R.H. \& KIDD, D.J. (1963) The effect of suggestion under hypnosis on the peripheral circulation in man. Clinical Science, 25, 223.

BlaCk, S. \& Friedman, M. (1965) Adrenal function and the inhibition of allergic responses under hypnosis. British Medical Journal, 1, 562.

Black, S., Humphrey, J.H., Niven, J.S.F. (1963) Inhibition of Mantoux reaction by direct suggestion under hypnosis. British Medical Journal, 1, 1649.

Bowers, K. (1966) Hypnotic behaviour: the differentiation of trance and demand characteristic variables. Journal of Abnormal and Social Psychology, 71, 42.

Braid, J. (1843) Neurypnology. Churchill, London.

Butler, B. (1954) The use of hypnosis in the care of the cancer patient. Cancer, $7,1$.

Chaves, J.F. (1968) Hypnosis reconceptualized: An overview of Barber's theoretical and empirical work. Psychological Reports, 22, 587.

Chertok, L. (1966) Hypnosis. Pergamon Press, London.

Chertok, L. (1969) Motherhood and Personality, Psychosomatic Aspects of Personality. Tavistock, London.

ConN, J.H. \& ConN, R.N. (1967) Discussion of T. X. Barber's 'Hypnosis' as a causal variable in present-day psychology: a critical analysis. Journal of Clinical and Experimental Hypnosis, 15, 106.

Delay, J. \& Pichot, P. (1962) Abrégé de Psychologie. Masson, Paris.

D’EsLon, M. (1780) Observations sur le Magnétisme Animale. cit. Chertok, 1966.

Dingwall, E.J. (1967) Abnormal Hypnotic Phenomena. A Survey of Nineteenth Century Cases, Vol. 1 France. Churchill, London.

Dorcus, R.M. \& Kirkner, F.J. (1948) The use of hypnosis in the suppression of intractable pain. Journal of Abnormal and Social Psychology, 43, 237.

Evans, F.J. (1966) Current developments in experimental hypnosis. Proceedings of the American Psychological Association. cit. Chaves, 1968.

FreUd, S. (1917) Introductory Lectures on Psycho-Analysis. Allen \& Unwin, London, 1922.

Freud, S. (1921) Group Psychology and the Analysis of the Ego. Hogarth, London.

Freud, S. (1925) An Autobiographical Study. Hogarth, London, 1935.

Gill, M. \& Brenman, M. (1959) Hypnosis and Related States. International Universities Press, New York.

Halliday, A.M. \& Mason, A.A. (1964) The effect of hypnotic anaesthesia on cortical responses. Journal of Neurology, Neurosurgery and Psychiatry, 27, 300.

HilgaRD, E.R. (1964) The motivational relevance of hypnosis. In: Symposium on Motivation (Ed. by M. R. Jones), cit. Chaves, 1968. Nebraska Press, Lincoln, Nebraska.

HilgaRD, E.R. \& TART, C.T. (1966) Responsiveness to suggestions following waking and imagination instructions and following induction of hypnosis. Journal of Abnormal and Social Psychology, 71, 196.
James, W. (1890) Principles of Psychology, Vol. 2. Macmilla ొొ London.

JONES, E. (1910) The action of suggestion in psychotherap Journal of Abnormal and Social Psychology, reprinted as Chap. 12 in: Papers on Psychoanalysis. William Wood; New York, 1913.

Kaplan, E.A. (1960) Hypnosis and pain. Archives of Generat Psychiatry, 2, 567.

Ludwig, A.M. \& LYLE, W.H. Jr (1964) Tension inductio产 and the hyperalert trance. Journal of Abnormal and Socim Psychology, 69, 70.

Maher-Loughnan, G.P. (1970) Hypnosis and asthmæ. International Journal of Clinical and Experimental Hyp nosis, 18, 1.

Maher-Loughnan, S.P. \& Kinsley, B.J. (1968) Hypnos $\vec{P}$ for asthma-a controlled trial: a report to the Research Committee of the British Tuberculosis Association British Medical Journal, 4, 71.

Malmo, R.D., Boag, T.J. \& Raginsky, B.R. (1954) Electræ myographic study of human deafness. Journal of Clinicä and Experimental Hypnosis, reprinted in: Psychopatholog $\underline{k}$ (Ed. by C. F. Reed, I. E. Alexander \& S. S. Tomkinst. Science Editions, Harvard University Press, Harvard 1964 r

Mandy, A.J., Mandy, T.E., Farkas, R. \& Scher, E. (195 Is natural childbirth natural? Psychosomatic Medicine, 143 431.

Merskey, H. \& Spear, F.G. (1967) Pain: Psychological and Psychiatric Aspects. Baillière, Tindall \& Cassell, Londor?

MerskeY, H. \& ToNGE, W.L. (1965) Psychiatric Illnes $\vec{x}$ Baillière, Tindall \& Cassell, London.

OsWALD, I. (1962) Sleeping and Waking. Elsevier, Amsterdarf

SACERDote, P. (1962) The place of hypnosis in the relie of severe protracted pain. American Journal of Clinical Hop nosis, 4, 150.

SACERDOTE, P. (1965) Additional contributions to the hypatherapy of the advanced cancer patient. American Joveriat of Clinical Hypnosis, 7, 308.

SACERdote, P. (1966) Hypnosis in cancer patients. America Journal of Clinical Hypnosis, 9, 100.

SARBIN, T.R. (1950) Contributions to role-taking theory. Hypnotic behaviour. Psychological Review, 57, 255.

SCHILDER, P. (1956) The Nature of Hypnosis. Internationaf Universities Press, New York.

SHOR, R.E. (1959) Hypnosis and the concept of the generaB ized reality orientation. American Journal of Psycho therapy, 13, 582.

SHOR, R.E. (1962a) Physiological effects of painful stimulation during hypnotic analgesia under conditions designee to minimize anxiety. International Journal of Clinical an Experimental Hypnosis, 10, 183.

SHOR, R.E. (1962b) On the Physiological Effects of Painf Stimulation During Hypnotic Analgesia. Basic Issues fog Further Research in Hypnosis: Current Problems, 1962 (Ed. by S. H. Estabrooks). Harper \& Row, London.

SIM, M. (1968) Guide to Psychiatry. Livingstone, Edinbrugh?

Sinclair-Gieben, A.H.C. \& Chalmers, D. (1959) Evalual tion of treatment of warts by hypnosis. Lancet, ii, 480 .

TART, C.T. (1969) Altered States of Consciousness, p. 229. John Wiley, New York. 